\title{
Conservation of a historic building through sympathetic thermal enhancement
}

\author{
J. Stinson, J. Bros Williamson, A. Reid \& J. Currie \\ Scottish Energy Centre, Institute for Sustainable Construction, \\ Edinburgh Napier University, UK
}

\begin{abstract}
This paper documents research undertaken by the Scottish Energy Centre at Edinburgh Napier University to refurbish a historic library building by means of thermal improvements. The interventions selected were specifically chosen to minimalise any impact on the architectural integrity of the building.

The study involved thermally enhancing the ceiling using a hygroscopic insulation material (200mm wood fibreboards). The objective was to measure the thermal transmittance and hygrothermal performance of the building, both pre and post intervention, with the aim of reducing heat loss without causing condensation problems.

The research demonstrated that, through the use of a modern, natural insulation material, the thermal transmittance (U-value) was reduced from 1.3 to 0.2 $\left(\mathrm{W} / \mathrm{m}^{2} \mathrm{~K}\right)$ - reducing the buildings energy consumption and associated carbon emissions, but most importantly conserving thermal comfort and preserving the buildings literary content. The hygrothermal analysis showed that the natural, vapour permeable insulating material altered the hygrothermal profile of the attic space. Extended monitoring of this environment detected conditions for one prolonged condensation episode However; visual surveys suggest that the hygroscopic insulation material acted to mitigate any detrimental effects of condensation build-up.

Keywords: conservation, preservation, historic building, retrofit, thermal, hygrothermal.
\end{abstract}

\section{Introduction}

Within the context of building conservation, the methods used to thermally refurbish historic dwellings are amongst the most highly deliberated and contested 
issues in the built environment; combining social, cultural, environmental and economic considerations.

Many historic buildings in the UK are constructed with a pitched, timberframed roof, of which the internal area is referred to as a loft or attic space. With government commitments to reduce energy consumption from buildings and improving energy efficiency, many homes have subsequently had loft insulation installed (DECC [1], Scottish Government [2]). The addition of loft insulation to the ceiling is still perceived as one of the most effective ways to reduce heat loss within the building envelope. This is particularly evident when thermally retrofitting historic buildings, often characterised by solid stone walls which are commonly $500-600 \mathrm{~mm}$ in thickness. These building types are often referred to as 'hard-to-treat', due to the difficulty associated with thermally enhancing the building elements such as solid walls, windows and solid floors.

Reducing the thermal transmittance of buildings, especially historical buildings, should not compromise the building ability to handle and move moisture (Hyslop and Hermann [3]). An insulated layer added to a ceiling will change the rate at which the temperature drops as it passes through the element. In the case of loft insulation, the unheated attic space above is referred to as a 'cold roof' space. Depending upon the vapour resistance value of the insulation material, there can potentially be an increase in the risk of liquid phase water being deposited on the cold side of the insulation layer. This risk is further exacerbated when other retrofit activities are undertaken to reduce ventilation heat loss, forcing the moisture laden warm air to diffuse into a much colder space often with higher moisture levels (Sanders [4]).

This paper describes the findings from an in-situ hygrothermal performance study conducted on the 'cold roof' space of a historic building in Scotland. The aim of this research was to categorise the hygrothermal performance of the ceiling and roof space both before and after the property was thermally upgraded, using a natural insulation with a low vapour resistance value. The added objective was to establish whether the addition of the insulation layer had any impact on the levels of condensation risk.

\subsection{Building and material characteristics}

The Category B listed library building was built in the late 17th century to store a collection of books and artefacts belonging to Archbishop Robert Leighton (16111684). At the time of construction, the building was the first purpose built library in Scotland. Today, the library is a well-known landmark within the small town of Dunblane, in central Scotland.

The library has a simple rectangular footprint with masonry lime bonded walls and crowstepped gables in the traditional Scottish vernacular, with chimney stacks on both gables (Figure 1). The elevations and gables have been harled with a wet dash cement finished with modern masonry paint. Such finishes are not considered ideal in building conservation terms in that they tend to lock in moisture. Bituminous roofing felt was installed under the slates during a period of refurbishment in the mid-1980s further preventing ventilation through the roof 


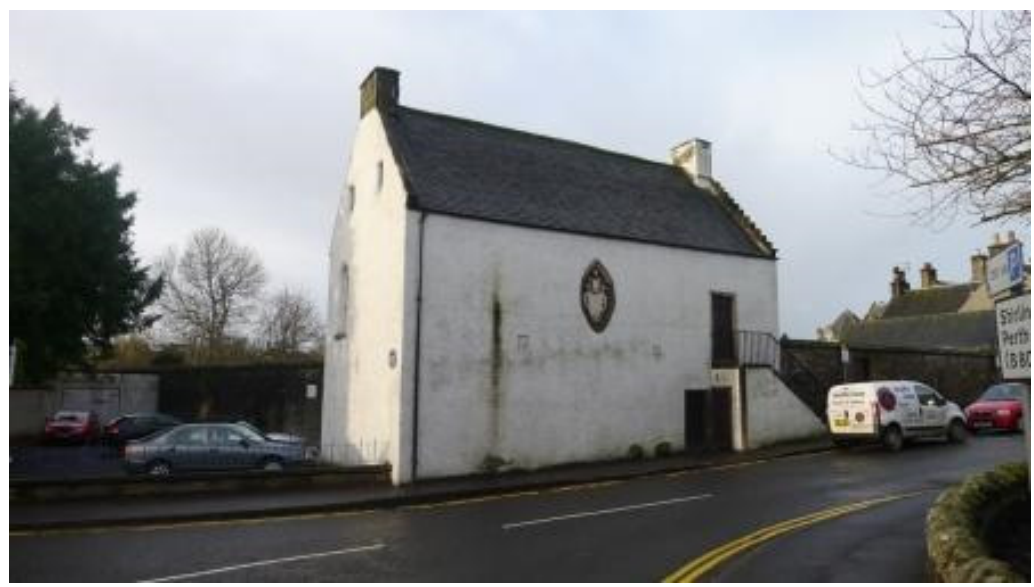

Figure 1: Leighton Library, Dunblane (2012).

fabric. Roofs with bituminous roofing felt in place typically require other methods of ventilation, such as roof vents, or venting at the ridge and eaves. In the case of the library the previous means of ventilating this roof space was through two large louvered vents on the south-east gable. These had been partially closed off, but were re-opened, ensuring an adequate degree of ventilation into the roof space (as shown in Figure 2).

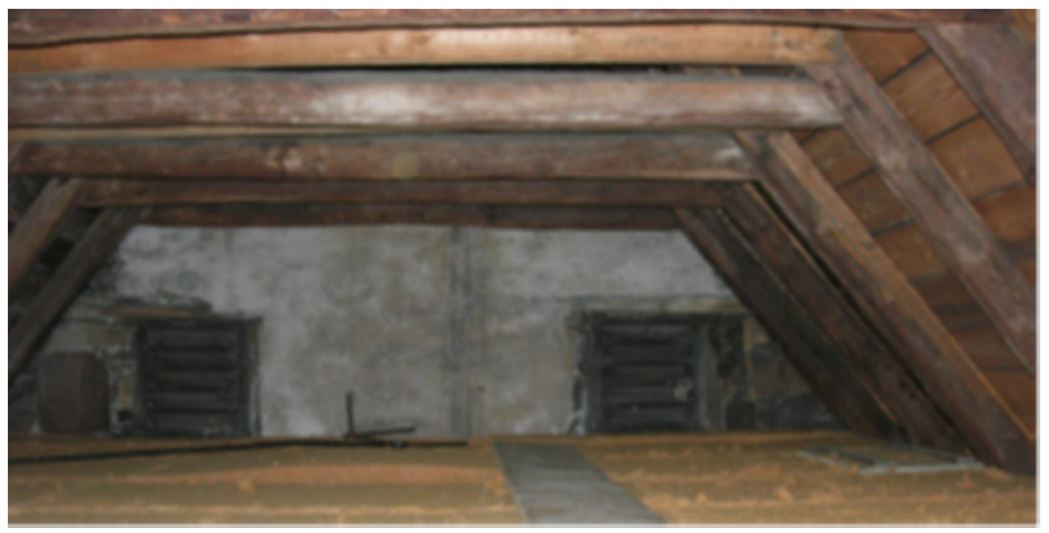

Figure 2: The louvered opening provides cross ventilation (courtesy of Historic Scotland).

Internally, the walls on the library level are finished with fine joinery, consisting mainly of book cases and timber panelling. Due to these features, internal wall insulation was not appropriate. Instead, the research team opted to insulate the ceiling, a method which was less invasive.

The insulation of the ceiling involved the installation of two layers of $100 \mathrm{~mm}$ wood fibreboard insulation directly above the internal timber panel finish. Made 
from a renewable resource (wood), this material was considered appropriate for traditionally constructed buildings, where the use of materials with a low resistance to liquid vapour and hygroscopic and high capillarity active qualities are considered important. The upper level of insulation finished $50 \mathrm{~mm}$ above the timber ceiling joists (see Figure 3). The wood fibreboard insulation used has a manufacturer stated thermal conductivity value of $0.038 \mathrm{~W} / \mathrm{mK}$ and a water vapour/diffusion resistance factor $3 \mu$ (mu-value) (BS EN ISO 10456: 2007 [5]).
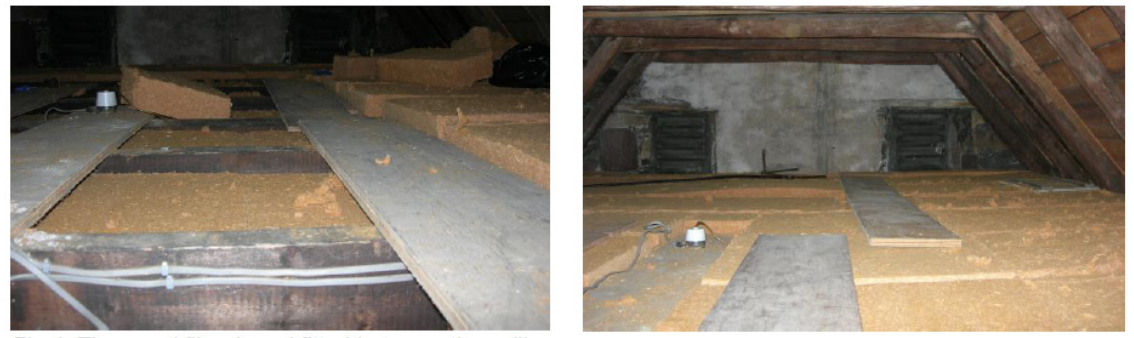

Figure 3: Photographs of wood fibreboard insulation. Crawl boards were used to assist installation (courtesy of Historic Scotland).

\section{Thermal transmittance}

This section sets out the methodology used to obtain thermal transmittance data for Leighton library and presents the subsequent results.

\subsection{Test methodology}

Measuring the thermal transmittance, or U-value, provides a measure of the thermal performance of the building envelope. The U-value is defined in ISO 7345:1996 [6] as the "heat flow rate in the steady state divided by the area and the temperature difference between the surroundings on each side of a system". The unit of measurement is watts per meter squared degree Kelvin $\left(\mathrm{W} / \mathrm{m}^{2} \mathrm{~K}\right)$. The in-situ U-value measurements were undertaken using the guidance set out in ISO/DIS 9869-1:1994 Thermal insulation, Building elements, In-situ measurement of thermal resistance and thermal transmittance - Part 1: Heat flow meter method [7], (now BS ISO 9869-1:2014 [8]). This established methodology is endorsed by experienced practitioners such as Baker $[9,10]$, Rye [11] and Currie et al. [12].

The in-situ U-values were measured using thermopile-based heat flux transducers (Hukseflux HFP01) of $80 \mathrm{~mm}$ diameter and $5 \mathrm{~mm}$ thickness, providing a typical accuracy of $\pm 10 \%$. In addition, K-type thermocouples were used to record temperatures, connected to Grant Squirrel data loggers with 24 bit A-D conversion resolution. The transducers were attached internally to the underside of the ceilings timber panelling. Two of these transducers were co-located in order to ensure spatial averaging, and to provide mitigation against potential equipment failure. The pre-intervention U-value monitoring took place in January 2012 over a 
21-day monitoring period. The post-intervention monitoring took place over 14 days in March 2012. To obtain a baseline U-value, pre-intervention measurements were taken. Following the installation of the ceiling insulation, the U-values were re-measured, thus providing the means to compare the pre- and post-intervention U-value data.

\subsection{Thermal transmittance: U-value results}

The U-values for the ceiling, both pre- and post-intervention, were calculated using the techniques described in BS EN ISO 6946:2007. Building components and building elements: thermal resistance and thermal transmittance: calculation methods [13]. Pre-intervention U-value for the ceiling was calculated to be $1.9 \mathrm{~W} / \mathrm{m}^{2} \mathrm{~K}$ and the insulated ceiling U-value was calculated to be $0.18 \mathrm{~W} / \mathrm{m}^{2} \mathrm{~K}$ (BRE [14]), providing an estimated 91\% improvement.

The in-situ thermal performance of the upper floor ceiling was measured prior to work taking place, achieving a U-value of $1.3 \pm 10 \% \mathrm{~W} / \mathrm{m}^{2} \mathrm{~K}$, this is $32 \%$ lower than the calculated U-value $\left(1.9 \mathrm{~W} / \mathrm{m}^{2} \mathrm{~K}\right)$. The monitoring of the U-value of the insulated ceiling showed that the measured thermal performance was improved by $85 \%$ to $0.2 \pm 10 \% \mathrm{~W} / \mathrm{m}^{2} \mathrm{~K}$.

The measured in-situ data is shown in Table 1.

Table 1: Pre- and post-intervention monitoring: temperature, relative humidity and thermal transmittance values.

\begin{tabular}{|c|c|c|}
\hline Temperature & $\begin{array}{c}\text { Relative } \\
\text { humidity }\end{array}$ & $\begin{array}{c}\text { Thermal } \\
\text { transmittance } \\
\text { (U-value) }\end{array}$ \\
\hline
\end{tabular}

Pre-intervention

(January 2012)

\begin{tabular}{|l|c|c|c|}
\hline Internal & $12^{\circ} \mathrm{C}$ & $69 \%$ & \multirow{2}{*}{$1.3 \mathrm{~W} / \mathrm{m}^{2} \mathrm{~K}$} \\
\hline External & $2^{\circ} \mathrm{C}$ & $95 \%$ & \\
\hline
\end{tabular}

Post-intervention

(March 2012)

\begin{tabular}{|l|c|c|c|}
\hline Internal & $15^{\circ} \mathrm{C}$ & $57 \%$ & \multirow{2}{*}{$0.2 \mathrm{~W} / \mathrm{m}^{2} \mathrm{~K}$} \\
\cline { 1 - 2 } External & $1{ }^{\circ} \mathrm{C}$ & $69 \%$ & \\
\hline
\end{tabular}

\section{Hygrothermal findings}

This section sets out the methodology used to obtain hygrothermal data for Leighton library and presents the subsequent results.

\subsection{Test methodology}

Four Tinytag sensor-data loggers were used to measure temperature and relative humidity. The location of the loggers is shown below in Table 2. 
Table 2: $\quad$ Location of Tinytag sensor-data loggers.

\begin{tabular}{|l|l|}
\hline Our reference & \multicolumn{1}{c|}{ Location description } \\
\hline Data set 1 & Internally (the main library area) \\
\hline Data set 2 & $\begin{array}{l}\text { The interface between ceiling and the attic (pre- } \\
\text { intervention)/interface between ceiling insulation (post- } \\
\text { intervention) }\end{array}$ \\
\hline Data set 3 & $\begin{array}{l}\text { Above the joists (pre-intervention) / } \\
\text { Interface between insulation and attic (post-intervention) }\end{array}$ \\
\hline Data set 4 & Externally \\
\hline
\end{tabular}

These loggers recorded at 15 minute sampling rate, with an accuracy of $\pm 0.4^{\circ} \mathrm{C}$ for temperature and $\pm 3 \%$ for relative humidity. The loggers recorded 21 days of data (19th Jan-8th Feb, 2012) before the insulation was added, providing baseline data. The loggers were then reactivated after the insulation was added, recording 494 days of data (20th March, 2012-27th July, 2013).

The data from the 4 loggers was used to construct a dewpoint margin for this hygrothermal analysis. This analysis was undertaken to identify times when the temperature and relative humidity conditions were conducive for liquid phase condensation to appear on the upper (cold) side of the insulation.

The dewpoint margin (DPM) is the difference between the dewpoint temperature and the recorded air temperature. The dewpoint temperature is calculated from the relationship between the recorded air temperature and the relative humidity. The DPM is reported as temperature $\left({ }^{\circ} \mathrm{C}\right)$, the interpretation of dewpoint margin (DPM) profile corresponds to a relationship analysis which identifies how close the profile line is to $0^{\circ} \mathrm{C}$. The DPM is $0^{\circ} \mathrm{C}$ when the monitored relative humidity for that time is $100 \%$ for the given temperature which is a proxy for liquid condensation.

\subsection{Hygrothermal results}

The dewpoint margin data for the pre-intervention (uninsulated) and postintervention (insulated) monitoring periods have been overlaid and plotted in Figure 4. The two loggers located at the two critical interfaces are likely to experience condensation episodes have been plotted. The monitoring period shown in Figure 4 displays 21 days in January/February during 2012 for preintervention data and for post-intervention data recorded in 2013. The lines are numbered for comparison and relate to the logger placement described in Section 4.1.

The data shows that during the 21-day pre-intervention monitoring period before the ceiling was insulated, conditions for a condensation episode were not detected. This is noted as none of the data recorded in the attic reached $0^{\circ} \mathrm{C}$, which 
is the point at which a condensation episode is most likely to occur. Data sets 2 and 3, pre-intervention are similar in pattern and magnitude because they are only separated by $150 \mathrm{~mm}$ of open space, although one of the uninsulated data sets (data set 2) recorded slightly higher temperatures and relative humidity levels being transferred from the library below.

Data set 2 recorded during post-intervention monitoring at the ceiling and insulating interface shows a notably increased DPM, meaning it did not experience any condensation episodes. This was to be expected as this interface is the warmest and driest given the insulation type and proximity to the internal space below.

Data set 3 recorded during post-intervention monitoring at the interface between the insulation and attic space was the interface where it was expected to see the largest variation in DPM pattern. Condensation conditions are mostly likely to be witnessed at this interface. The magnitude and pattern of the data recorded at this interface is considerably different when compared to the preintervention data recorded over the same time the year before. The DPM pattern is distinctively different at the start and end of this comparative period, recorded conditions very likely to give rise to condensation. Analysis of the internal and external weather conditions show that internal DPM recorded before the insulated was added $(\mathrm{M}=7.19, \mathrm{SE}=0.01)$ and that recorded after insulation was added $(\mathrm{M}=11.17, \mathrm{SE}=0.17)$ were statistically different from each other, $\mathrm{t}(2016)=$ $226, p<0.00$. The same dependent T-test was conducted on the external DPM data, the pre-intervention external DPM $(\mathrm{M}=0.64, \mathrm{SE}=0.03)$ was significantly different from the external DPM recorded during the post-intervention monitoring $(\mathrm{M}=0.08, \mathrm{SE}=0.01), \mathrm{t}(2016)=18, \mathrm{p}<0.00$.

It should be noted that the data sets above are not directly comparable, due to the nature of changing weather patterns and occupancy rates during longer

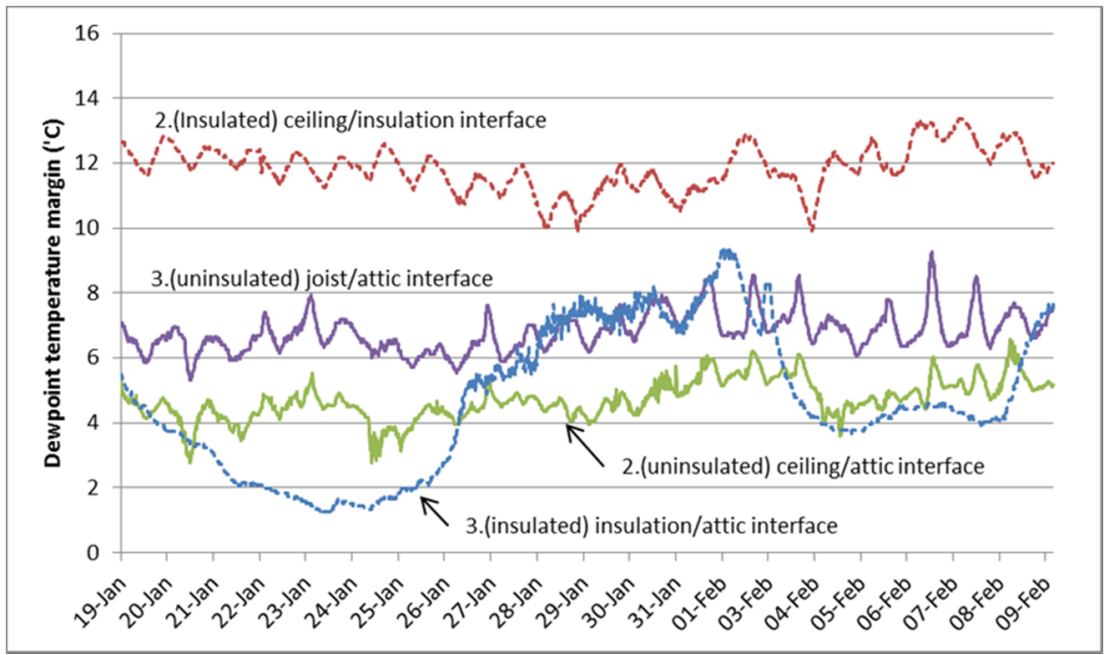

Figure 4: Dewpoint margins two loggers located in attic space 19th Jan9th Feb, for 2012 (uninsulated) and 2013 (insulated). 
monitoring periods. Analysis of the full 494 days of post-intervention monitoring shows that the critical data set (the interface between the insulation and attic being the data set most likely to record $0^{\circ} \mathrm{C}$ DPM) recorded only one episode where condensation was likely to occur. This single episode appeared continuously for 13 days between 1st and 15th October. For the remainder of the monitoring period, no further conditions which were conducive to condensation were recorded.

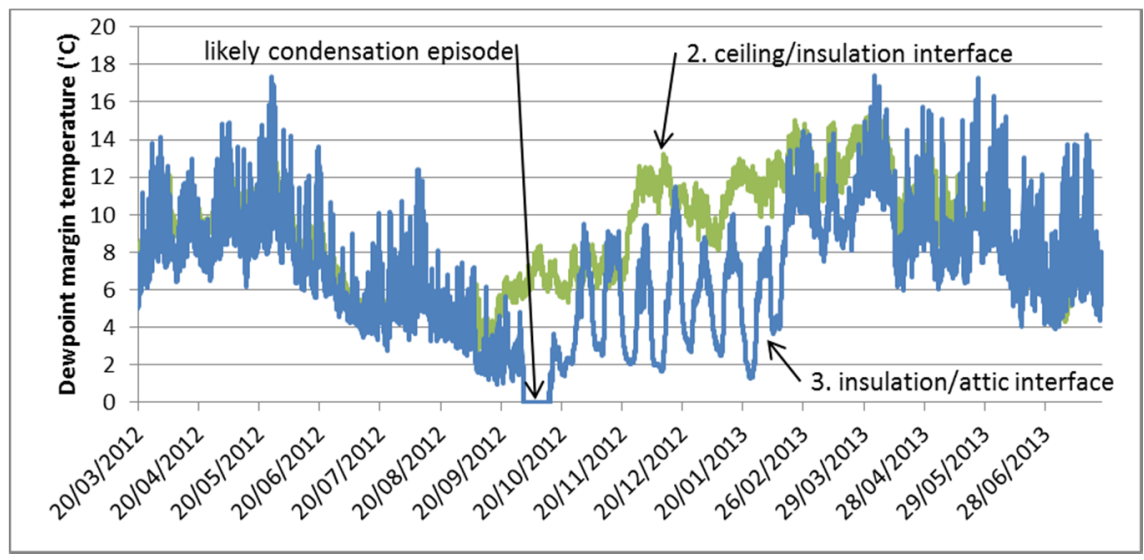

Figure 5: Post-intervention dewpoint margin for the two loggers above and below insulation in attic space.

\section{Conclusions}

Refurbishment and, in particular, the thermal improvement of listed and historic buildings are perceived by many in the construction industry as troublesome and technically challenging. Indeed, such are the challenges that these buildings are often labelled as being 'hard to treat'.

In order to ensure that historical buildings are preserved, are energy efficient and economically viable, it is important to carefully consider methods and materials which will be sympathetic and understanding to the buildings original fabric and characteristics.

The aim of this study was to provide evidence which demonstrates that thermal improvements can be achieved using insulation materials and techniques that are not only effective in terms of thermal retention, but sympathetic to the original construction method.

The research demonstrates, through the use of modern natural insulation, that the thermal transmittance (U-value) was reduced from 1.3 to $0.2\left(\mathrm{~W} / \mathrm{m}^{2} \mathrm{~K}\right)$ lowering heat loss, thus heating requirements. The hygrothermal analysis showed that the addition of $200 \mathrm{~mm}$ wood fibreboard insulation does change the hygrothermal profile of the attic space, reducing the dewpoint margin of the interface between the insulation and cold attic.

The study undertaken at Leighton Library has shown that a considerable improvement can be made to the thermal performance of a traditional roof space 
using a natural, vapour permeable material. Whilst refurbishment work to historic buildings (especially those with high historic value) requires careful consideration and rigorous planning on a case-by-case basis, the methodology adopted for Leighton Library is widely applicable to many other historic buildings in Scotland.

Selecting the appropriate materials, location and application for insulation in older buildings will depend on several factors including; vapour permeability and thermal conductance of materials, fixing methods, historic significance of the internal linings and finishes, the available budget, and the level of disruption that the occupant is willing to tolerate.

For example, mineral wool, which is a much more common (and less expensive) insulation material than wood fibreboard, has a lower water vapour/diffusion resistance factor of $1 \mu(\mathrm{mu})$ but a similar thermal conductivity value of between 0.03 and $0.04 \mathrm{~W} / \mathrm{mK}$ (BS EN ISO 10456: 2007 [5]).

However, wood fibreboard insulation, unlike mineral wool, demonstrates superior hygroscopic qualities and is highly capillarity active; which means if a condensation event is to occur, the material possess the ability to handle transient liquid moisture without adversely affecting the thermal and physical qualities.

\section{Further research}

Significant progress into the thermal upgrading of traditional buildings has been made in recent times and, whilst these have been incorporated in a manner sympathetic to the building needs, questions have been raised in respect of their impact on the complex and dynamic mechanisms of moisture transmission. Limited empirical data exists in respect of dynamic moisture capacities of traditional structures and this research forms part of a longer term study aiming to evaluate the hygrothermal performance of a number of common building elements both before and after the addition of thermal improvement measures.

The results in this paper contribute to the increasing evidence available on the thermal performance of traditional building elements. This will be a useful contribution to a knowledge base, which can be used towards the development of suitable energy performance strategies for historic buildings in the future.

\section{Acknowledgements}

The authors gratefully acknowledge Dunblane Cathedral and Leighton Library Trust. The research would not have been possible without the support provided by Historic Scotland Conservation Directorate. For further information on the refurbishment of Leighton library, please access Historic Scotland [15].

\section{References}

[1] DECC, Estimates of Home Insulation Levels in Great Britain: July 2013. Available at: https:/www.gov.uk/government/uploads/system/uploads/ attachment_data/file/240190/statistical_release_estimates_home_insulatio n_levels_gb_july_13.pdf 
[2] Scottish Government. Scottish House Condition Survey - key findings 2012. Available at: http://news.scotland.gov.uk/News/Scottish-HouseCondition-Survey-key-findings-2012-723.aspx

[3] Hyslop. E. \& Hermann. C., Moisture in sustainable building conservation. Hygrothermal seminar. Conference: Edinburgh, 24 Feb, 2015.

[4] Sanders. C., Modelling condensation and airflow in pitched roofs. BRE IP 5/06, 2006.

[5] BS EN ISO 10456: 2007, Building materials and products - Hygrothermal properties - Tabulated design values and procedures for determining declared and design thermal values. London: BSI.

[6] BS EN ISO 7345:1996: thermal insulation: physical quantities and definitions. (Identical with 1987 ed.) London: BSI.

[7] ISO/DIS 9869-1:1994 Thermal insulation, Building elements, In-situ measurement of thermal resistance and thermal transmittance - Part 1: Heat flow meter method. London: BSI.

[8] BS ISO 9869-1:2014 Thermal insulation, Building elements, In-situ measurement of thermal resistance and thermal transmittance - Part 1: Heat flow meter method. London: BSI.

[9] Baker, P., In situ U-value measurements in traditional buildings: Preliminary results. (Historic Scotland Technical Paper 2) [PDF] Edinburgh, 2008: Historic Scotland. Available at: www.historicscotland.gov.uk/uvalue_measurements_traditional_buildings. pdf

[10] Baker, P., U- values and traditional buildings: in situ measurements and their comparisons to calculated values. (Historic Scotland Technical Paper 10) $[\mathrm{PDF}]$ Edinburgh: Historic Scotland, 2011. Available at: www.historicscotland.gov.uk/hstp102011-u-values-and-traditionalbuildings.pdf

[11] Rye, C., U-value report (SPAB Research Report; no.1). Revised ed. [PDF] London: SPAB, 2011. Available at: www.spab.org.uk/downloads/ The\%20SPAB\%20Research\%20Report\%201.\%20U-value\%20Report.\% 20Revised\%20October\%202011.pdf

[12] Currie, J., Bros Williamson, J. \& Stinson, J. HS Technical Paper 19a: Monitoring Thermal Upgrades to Ten Traditional Properties, 2013. Available at: http://www.historic-scotland.gov.uk/technicalpaper19.pdf

[13] BS EN ISO 6946:2007. Building components and building elements: thermal resistance and thermal transmittance: calculation methods. London: BSI.

[14] BRE. Calculation of U-value software. Following conventions in BRE BR 442,2014

[15] Historic Scotland, HS Refurbishment Case Study 09: Leighton Library, 2014. Available at: http://www.historic-scotland.gov.uk/refurb-case-study9.pdf 